\title{
Varicose Vein Reccurence After Pregnancy: Influence of The Preservation of The Saphenous Vein in Nullipara Patients
}

Pittaluga P. ${ }^{1}$, Chastagnet S. ${ }^{1}$

${ }^{1}$ França.

E-mail: paulpittaluga@hotmail.com

Pittaluga, P.; Chastanet, S. 2013. Varicose Vein Reccurence After Pregnancy: Influence of The Preservation of The Saphenous Vein in Nullipara Patients, p.81. In: Bastos, Francisco Reis. Anais do V Simpósio Internacional de Flebologia [Blucher Medical Proceedings n.1 v.1]. São Paulo: Blucher, 2014

http://dx.doi.org/10.5151/medpro-flebo-SIF_53

\section{Background}

The pregnancy is a risk factor for recurrence after a surgical treatment of varices. The aim of this study is to evaluate the influence of the preservation of the saphenous vein (SV) for the treatment of varices, in nullipara patients who had a pregnancy following the treatment.

\section{Methods}

We have included in this retrospective study the nulliparas who had a pregnancy following the first surgical treatment of varices (FSTV), leading to varicose recurrence (REVAS) and reoperation (REOP).

Two periods were compared: 1 - January 1998 to December 2002: the referent FSTV among nullipara patients consisted of ablation of the SV (T1). 2 - January 2003 to December 2007: the referent FSTV was phlebectomy with preservation of the SV (T2).

The extent of the treated varices was evaluated according to the number of zones treated (NZT) by phlebectomy, with each lower limb (LL) divided into 32 zones.

\section{Results}

From January 1998 to December 2007 a total of 44 LLs were operated on in 33 patients who matched the criteria of inclusion. Among these patients, 19 have been operated on during T1 (cohort 1) and 14 during T2 (cohort 2). The comparison of the population characteristics for the two cohorts at the time of FSTV showed no differences (Table 1). The mean time between the FSTV and the pregnancy was 26.0 months in cohort 1 and 18.7 months in cohort 2 (NS), and between the pregnancy an the REOP was 13.8 months in cohort 1 and 18.3 months in cohort $2(P<.05)$. The comparison of the two cohorts at the time of REOP showed a higher frequency of symptoms, redo surgery at the sapheno-femoral confluence, NZT and postoperative lymphatic complications in the cohort 1 (Table 2). 
Table 1 - Characteristics of population and procedures for cohort 1 and cohort 2 at the time of FSTV

\begin{tabular}{|c|c|c|c|}
\hline & Cohort 1 & Cohort 2 & $p$ \\
\hline LLS & 25 & 19 & \\
\hline Age (average) & $30.8 y$ & $28.7 y$ & NS \\
\hline CEAP class C2 & $96 \%$ & $95 \%$ & NS \\
\hline Presence of symptoms & $72 \%$ & $74 \%$ & NS \\
\hline GSV reflux & $88.0 \%$ & $84.2 \%$ & NS \\
\hline SV preservation & $8.0 \%$ & $78.9 \%$ & $<.05$ \\
\hline
\end{tabular}

\begin{tabular}{|c|c|c|c|}
\hline & Cohort 1 & Cohort 2 & $\mathrm{p}$ \\
\hline LLS & 25 & 19 & \\
\hline CEAP class C2 & $90.9 \%$ & $95.5 \%$ & NS \\
\hline Presence of symptoms & $79.1 \%$ & $31.1 \%$ & $<.05$ \\
\hline $\begin{array}{l}\text { Redo surgery at the } \\
\text { sapheno-femoral confluence }\end{array}$ & $52.0 \%$ & $11.0 \%$ & $<.05$ \\
\hline NZT & 7.6 & 6.1 & $<.05$ \\
\hline Postop complication (lymphatic) & $8.0 \%$ & $0.0 \%$ & NS \\
\hline
\end{tabular}

\section{Conclusion}

The surgical treatment of varices in nullipara patients by phlebectomy, with preservation of the SV, may make it possible to reduce the complexity, signs, and symptoms in the event of varicose vein recurrence after pregnancy.

Key words: varicose vein, phlebectomy, recurrence, pregnancy. 